Preprints of the

Max Planck Institute for

Research on Collective Goods

Bonn 2017/17

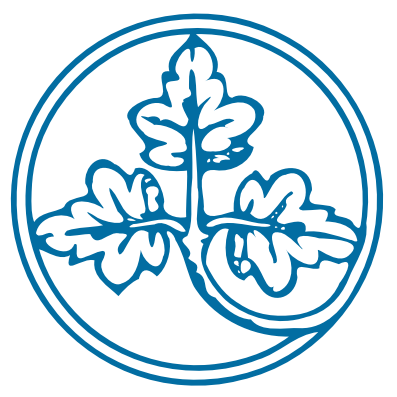

Behaviorally Efficient

Remedies

An Experiment

Christoph Engel

Lars Freund

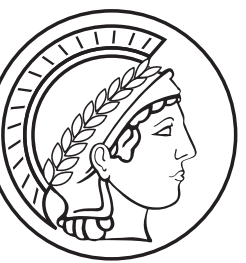




\section{Behaviorally Efficient Remedies An Experiment}

Christoph Engel / Lars Freund

August 2017 


\title{
Behaviorally Efficient Remedies \\ An Experiment ${ }^{*}$
}

\section{Christoph Engel / Lars Freund}

\begin{abstract}
Under common law, the standard remedy for breach of contract is expectation damages. Under continental law, the standard is specific performance. The common law solution is ex post efficient. But is it also ex ante efficient? We use experimental methods to test whether knowing that non-fulfilment will only lead to damages deters mutually beneficial trade. The design excludes aversion against others willfully breaking their promises. We find that there is indeed less trade if specific performance is not guaranteed, provided the preference for the traded commodity is sufficiently pronounced.
\end{abstract}

JEL: C91, D02, D03, D61, D62, D64, H23, K12

Keywords: remedies, breach of contract, specific performance, expectation damages, reliance damages, donation, experiment

Helpful comments by Pascal Langenbach and André Schmelzer on an earlier version are gratefully acknowledged. Corresponding author: Prof. Dr. Christoph Engel, Max Planck Institute for Research on Collective Goods, Kurt-Schumacher-Straße 10, D 53113 Bonn, engel@coll.mpg.de 


\section{Introduction}

Beware of the dismal science! Much like Thomas Carlyle who in 1849 wanted slavery back (Carlyle 1849), modern lawyers who use the quote do not object to the analytic rigor of economic models, but to the normative conclusions derived from welfare theory. One of the hotly debated bones of contest is the "efficient breach of contract". While its proponents see efficient breach as the hidden rationale of the reluctance of common law to grant specific performance (Birmingham 1970, Goetz and Scott 1977, Posner 2014), opponents reject allocative efficiency as the prime purpose of contractual remedies (Friedmann 1989, Lewinsohn-Zamir 2012). One may however even criticize the efficient breach doctrine if one accepts allocative efficiency as the goal. One may point to problems with transaction cost (Macneil 1982), or one may shift attention to efficiency ex ante, and in particular to investment of a seller in precautions versus investment of a buyer in reliance (Schweizer 2006, Schweizer 2012, Stremitzer 2012). In this paper, we follow this tradition. But our critique is behavioral. We wonder whether legal orders forgo gains from trade if they refuse to enforce the letter of a contract and only grant expectation or reliance damages if a contract has not been fulfilled. Do individuals refrain from mutually beneficial exchange (and do not conclude a contract) if they cannot get specific performance? Do they have a positive willingness to pay for this remedy? Are legal orders well advised to grant specific performance since this remedy reflects the revealed preferences of their subjects? Is granting specific performance hence behaviorally efficient?

Much of the resistance against the efficient breach doctrine results from the fact that it allows a party to a contract to renege on its promise (Friedmann 1989). In this paper, we bracket this (legitimate) behavioral concern and focus on contracting partners' preferences. We thus adopt an ex ante perspective. Of course, ex ante prevoyant contracting parties can always mute the issue and stipulate the remedies they desire. If sellers anticipate that (some) buyers care about specific performance, they may offer this remedy, at an additional price. But despite the fact that there is freedom of contract, contract law serves a purpose. Most contracting parties do not only go by the legislative default since this saves transaction cost (Macneil 1982). They also assume that, for the standard relationship, the legislator got the balance of interests right. They thus assume the legal rule to be a majoritarian, not a penalty default (cf. Ayres and Gertner 1999).

Behavioral welfare economics is a challenging enterprise (Bernheim 2009, Bernheim and Rangel 2009). We do not have the ambition to define normatively desirable finite states for a population of individuals holding non-standard preferences. Our goal is more modest. We want to compare market outcomes if the remedy in case the contract fails is either specific performance, expectation damages, or reliance damages. Our prime variable of interest is trade: are individuals substantially more likely to engage in mutually beneficial exchange if there is an insurmountable degree of risk regarding contract fulfillment, but the remedy is specific performance? By behavioral efficiency we thus mean the propensity to conclude risky contracts. 
In the interest of generating clean and credible data, we go to the lab. We study two objects of trade on which arguably people's preferences differ substantially. In the first part of the experiment, we give participants a choice between 10 different items. In the third (and main) part, they have a chance to buy their preferred item at an attractive price. There is however a 25\% chance that exchange fails and the money goes to a person that has been randomly picked from the Berlin phonebook. We frame the legal remedies as independent contracts. Participants have the opportunity to spend some of their endowments on a supplementary contract that is meant to capture the essence of (a) specific performance, (b) expectation damages or (c) reliance damages. Contract (a) guarantees their preferred item, at an additional price. Contract (c) gives them their paid money back if the deal fails.

To elicit the individual monetary value of contract fulfilment, we run the second part of the experiment. Participants already have a chance to buy one unit of their preferred item, but face the $25 \%$ risk to receive a random item from the rest of the list instead. They can insure themselves against this risk. If they buy insurance, the risk is perfectly contained. In the third part of the experiment, we use their willingness to pay for insurance in the second part of the experiment as a markup. In the (b) expectation damages condition of the main experiment, if the deal fails participants receive the purchase price plus this markup. ${ }^{1}$

Using the strategy method (Selten 1967), each participant decides, for each of the three remedies, how much she is willing to pay for the remedy (using Becker, DeGroot et al. 1964), and whether she is willing to buy the item, either unconditionally or only conditional on actually being insured. At the outset, participants are informed that either the second or the third part of the experiment will be paid out, with equal probability.

We combine the within subjects manipulation of the three remedies with a between subjects manipulation. Between subjects, we offer two different commodities. In the Chocolate treatment, participants may buy two bars of a prime chocolate brand, at a price considerably below market prices. The list of flavors is in the appendix. In the Donation treatment, participants may choose between ten well-recognized charities. Donations are doubled up by the experimenter. The list of donations is in the appendix.

Results differ between the two commodities. Despite the fact that the chocolate is subsidized, the risk deters trade. Willingness to pay for either remedy is low. The large majority of participants prefers to keep their monetary endowments. There is no significant difference in terms of trade, or in terms of willingness to pay, between the three remedies. This is different for donations. Even if only reliance damages are available, more than $40 \%$ of all participants chose to make a donation intended for their preferred charity. Results are almost identical with expectation damages. However with specific performance, $55 \%$ chose to make a donation. In line with this, a larger proportion of participants are willing to spend some of their endowment on buying specific performance, rather than expectation or reliance damages. We

1 When they make their choices in the second part of the experiment, participants do not know what the third part will be about. 
conclude that granting specific performance is indeed behaviorally efficient, but only if individuals have sufficiently strong preferences for the traded commodity.

The remainder of the paper is organized as follows: in section 2 we relate our experiment to the literature and formulate hypotheses. In section 3 we explain the design of the experiment. Section 4 reports results. Section 5 concludes with discussion.

\section{Literature and Hypotheses}

The experimental literature on contractual remedies is still small. Most related to our experiment is the vignette study by Lewinsohn-Zamir (2013). She has given her lay participants six scenarios and has always asked them whether they prefer an in kind remedy (69\%) or monetary compensation (26\%). 46\% declared they would not switch to the contract allowing for breach against compensation whatever the discount. Those who would accept on average demanded $135 \%$ of the original price as compensation. Replicating the experiment with business people revealed an even stronger preference for the in kind remedy (79\%). They on average still ask for a $60 \%$ discount if they are at all willing to switch to the alternative contract. One may suspect these numbers to be excessively high. This is why an incentivized test is in order. The previous study asked for willingness to accept, which is generally higher than willingness to pay (Kahneman, Knetsch et al. 1990) (but see Zeiler and Plott 2005), one of our measures. This too promises a more conservative estimate. Most importantly, we also elicit the impact of the available remedy on trade, and therefore on efficiency.

Standard theory predicts that buyers overinvest in reliance on the contract if they are strongly protected. This is also what Sloof, Leuven et al. (2003) find in the lab, even when allowing for renegotiations after the risk has materialized (Sloof, Oosterbeek et al. 2006). In our design, reliance investments are not possible.

Several experiments test the behavioral dimension of breaching a contract. Wilkinson-Ryan and Baron (2009) find that participants express a greater desire to punish a person who breaches a contract in the interest of making a higher profit, rather than choking under the pressure of an unexpected increase in cost. Wilkinson-Ryan and Hoffman (2010) explain the strong reaction against violating a contractual obligation with aversion against being the sucker. However there is more breach if the contract stipulates liquidated damages, and thereby implicitly legitimizes breach (Wilkinson-Ryan 2010). If participants are explicitly told that specific performance is guaranteed, they become more litigant (Depoorter and Tontrup 2012).

The Donation treatment capitalizes on an experiment one of us has run with other co-authors. In that experiment, participants had a chance to donate a quarter of their endowment to one preselected charity. The amount was doubled up by the experimenter. There was a $20 \%$ chance that the donation would instead be used to finance a board dinner. In the treatment, participants could buy insurance against this risk. Willingness to pay for insurance was sub- 
stantial. On average, participants were willing to spend 44 Cents to make sure that a donation of $2.50 €$ does not reach an unintended recipient. If they could not insure against the risk, only $40 \%$ made a donation, while $70 \%$ did if insurance was available (Buijze, Engel et al. 2017). The earlier experiment has made us confident that participants would again be willing to make donations in the face of the risk that the donation is subverted, and that they would have a willingness to pay to remove or mitigate this risk. Yet the new experiment has a completely different research question. In this experiment we test the incentive effects of alternative contractual remedies.

In the experiment, the commodities are subsidized. In principle we therefore expect demand to be pronounced. Yet the commodities are selected such that there should be variance in preferences for the commodities on offer. Therefore participants should feel the loss in utility resulting from possibly not receiving the desired commodity. Specific performance protects them more strongly against this risk than expectation damages than reliance damages. We therefore expect

$\mathbf{H}_{1}$ : Willingness to pay for specific performance is higher than for expectation damages than for reliance damages.

If the risk materializes, participants have to pay for a commodity they desire less than another one, and that they have not selected themselves. Specific performance removes this concern completely. Expectation damages fully compensate participants for the money equivalent of the utility loss. Reliance damages at least make them break even. We expect this difference to affect the willingness to acquire the commodity in the first place

$\mathbf{H}_{2}$ : The willingness to acquire the commodity is higher if the regime in the case of contract failure is specific performance, rather than expectation damages, rather than reliance damages.

We have no directed hypothesis for the difference between the Donation and the Chocolate treatments. Chocolate is a traditional commodity. It is hard for someone not to like at least some flavor of chocolate. On the other hand many individuals have pronounced preferences over flavors. In the market, many goods come with express warranties. By contrast, donations can at best be protected indirectly, by the reputation of a donation intermediary. For all these reasons one might expect that participants are more inclined to protect a deal in chocolate. On the other hand participants might be more emotionally involved with a cause for which they give money than with the pleasure from eating their favorite chocolate. This might translate into more pronounced sensitivity for the difference between specific performance and its monetary equivalent, i.e. expectation damages. 


\section{Design}

To test our hypotheses, we conduct a laboratory experiment. The experiment consists of three parts, as shown in Figure 1. Participants know that either the second or the third part are payoff-relevant, with equal probability. In the first part, participants chose their preferred flavor of chocolate or charity. In the third part, participants decide whether they want to buy their preferred chocolate / to donate to their preferred charity. Using the strategy method, they make this choice for three different institutional environments. In the first environment, specific performance is available. In the second environment, expectation damages are available. In the third environment, reliance damages are available.

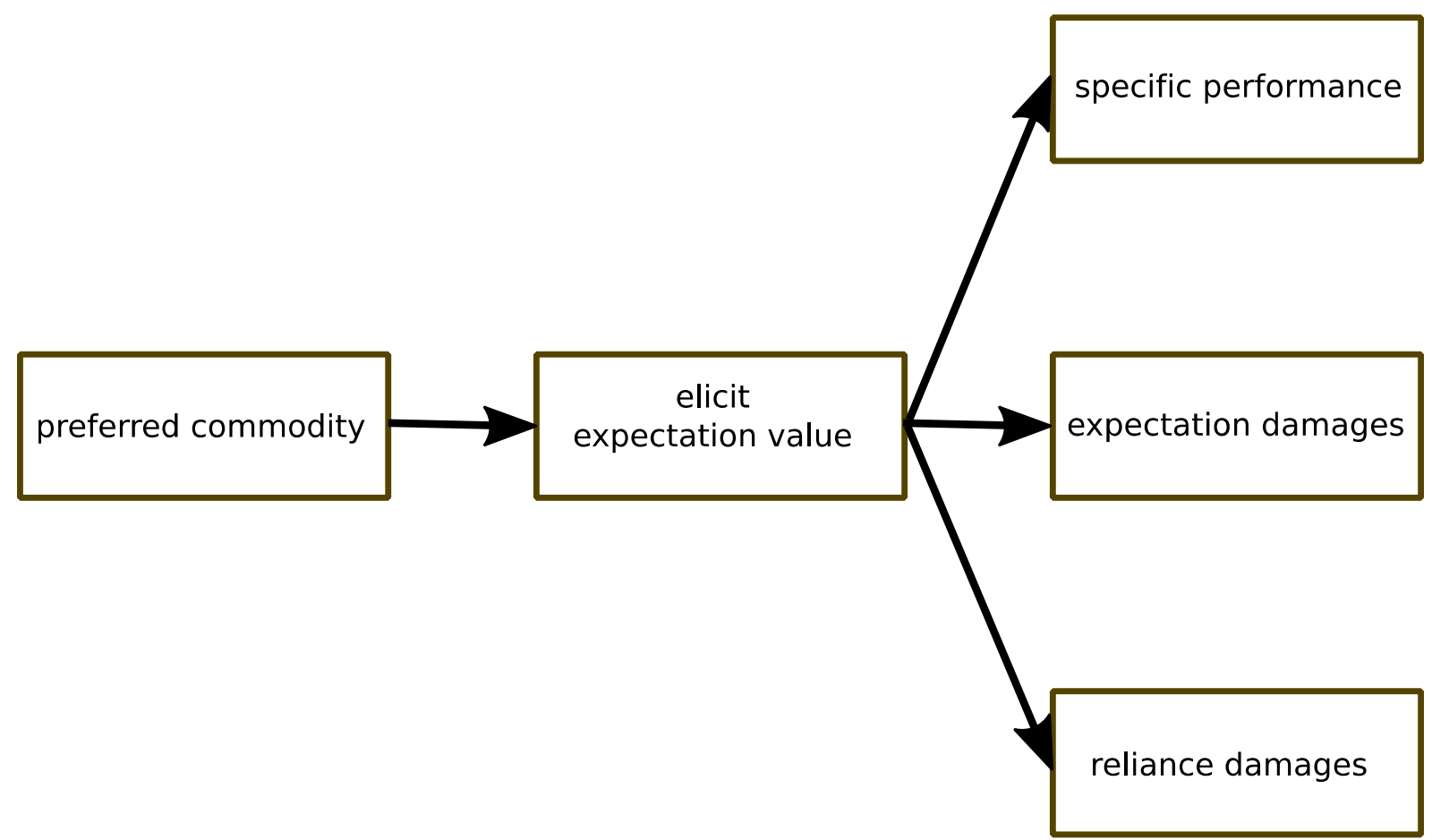

Figure 1

Design of the Experiment

Specifically, in the main experiment (part 3), participants are endowed with $5 €$. In the Charities treatment, they have the opportunity to keep their endowment, or to donate $2.50 €$ to their preferred charity. If they make a donation, the donated amount is doubled up by the experimenter. In the Chocolate treatment, they are offered to buy two bars of their favorite chocolate at a price of $2.50 €$. This is approximately half the price this chocolate would have in a store. For both commodities, participants know that there is a $25 \%$ probability that the deal fails. Their payments made for all failed deals go to a single person that has been randomly picked from the Berlin phone book.

Participants have the possibility to protect themselves against this risk. Using the strategy method (Selten 1967), participants are offered three alternative protection schemes. After the 
experiment, a random draw decided which of the three schemes is payoff relevant, with equal probability. The first scheme is meant to capture the essence of specific performance. If the deal fails and the random person receives the payment, the participant is made whole. The charity of choice receives $5 €$, or the participant receives two bars of her favorite chocolate. The third scheme is meant to capture the essence of reliance damages. If the risk materializes, the participant gets her money back. She may use that money to make a donation or to buy chocolate, respectively. But the recipient charity or the chocolate flavor are randomly picked from the remainder of the list. The charity or chocolate of choice is no longer available. This feature is meant to make sure that reliance damages and specific performance do not collapse.

The second scheme is meant to capture the difference between reliance and expectation damages. Doctrinally speaking expectation damages consist of pecuniary compensation for the difference in utility between donating to the preferred over a random charity; or for the difference in utility between receiving the favorite rather than a random flavor of chocolate. In the experiment, we get at this difference by the second part of the experiment. Participants are offered the same list of charities or chocolates. They pick their favorite. They are given another endowment of $5 €$ which they can spend on donating $2.50 €$ to their preferred charity, or on buying two bars of their favorite chocolate. Now there is a $25 \%$ risk that the donation instead goes to another randomly chosen charity from the list, or that they receive two bars of another randomly chosen flavor of chocolate. Participants can insure themselves against this risk. The insurance premium is determined by the mechanism of Becker, DeGroot et al. (1964), i.e. by a second price auction. The participant states her maximum willingness to pay for insurance. This statement is compared with a randomly chosen price in the interval $[0,2.50 €]$. If the statement is above this cutoff, the participant is insured and pays the cutoff price. Participants do not receive any information about the third part of the experiment before it starts. This procedure gives us an incentivized measure (in monetary terms) for the difference in utility between the participant's preferred option and all that can still be achieved after the deal has failed, namely acquiring a random item from the rest of the list.

In the second part of the experiment, participants are further asked to choose between three options: they do not want to make a donation/buy chocolate in the first place; they only want to make a donation/buy chocolate if they are effectively insured (i.e. if their stated willingness to pay was above the cutoff); they want to make a donation/buy chocolate even if they are not insured. Note that using the willingness to pay from the second part of the experiment as a markup in the third part gives us a fully incentivized measure for the difference between reliance and expectation damages. The insurance premium measures how much this participant was willing to spend to make sure that her favorite charity or chocolate is chosen. If we find a difference between willingness to donate / to buy chocolate, or willingness to pay for the respective protection scheme, between the specific performance and the expectation damages treatment, we know that it does not capture a difference in the pecuniary interest, but additional valuation for the respective choice being safe. 
In the main experiment (part 3), for each of the three remedies we separately elicit willingness to pay (again using Becker, DeGroot et al. 1964), and we give participants the same three options: not to make a donation/buy chocolate whether they are protected by the remedy or not; only conditional on being protected; whether or not they are protected.

In the interest of having more scope for explaining findings, we run a series of postexperimental tests. Arguably willingness to donate is related to participants' social value orientation, which we measure using Murphy and Ackermann (2014). In both parts of the experiment, participants face the risk that the deal fails. Their sensitivity towards failure might be related to their risk aversion. We measure constant relative risk aversion using Holt and Laury (2002). Yet in both versions of the experiment the risk is non-standard. Arguably in the Charities treatment, the risk is of an ethical nature, whereas in the Chocolate treatment it is of a recreational nature. In the interest of being able to discriminate between alternative dimensions of risk we also administer the domain specific risk scale by Blais and Weber (2006). We finally ask for demographic information.

All feedback is withheld until the very end of the experiment, so that choices in later parts are not influenced by the outcomes of earlier parts of the experiment.

120 individuals participated in the experiment, most of which were students of various majors. Mean age was 23.81 years. 59 participated in the Donation treatment, 61 in the Chocolate treatment. ${ }^{2} 60$ participants were female. The experiment was conducted in the Cologne EconLab in May 2017. Participants on average earned $12.36 €^{3}, 11.98 €$ in the Donation, and $12.73 €$ in the Chocolate treatment. Participants were invited using hroot (Bock, Baetge et al. 2014). The experiment was computerized using zTree (Fischbacher 2007).

\section{Results}

Both manipulations have worked well (Figure 2). Preferences for chocolate flavors are very balanced. Four flavors are preferred by five participants each, one by seven, two by eight and two by nine. For charities, there is more variance. Three charities are only chosen by a single participant, and one only by two participants. There is one charity each that is chosen by five, seven or eight participants. The three front-runners are either chosen by 11 (twice) or 12 participants (once).

2 The slight imbalance is due to invited participants not showing up.

3 Equivalent to $13.85 \$$ on the day of the experiment. Payoffs result from earnings from the first or second part of the experiment, from the tests for risk aversion and social value orientation, and a show-up fee of $4 €$. 


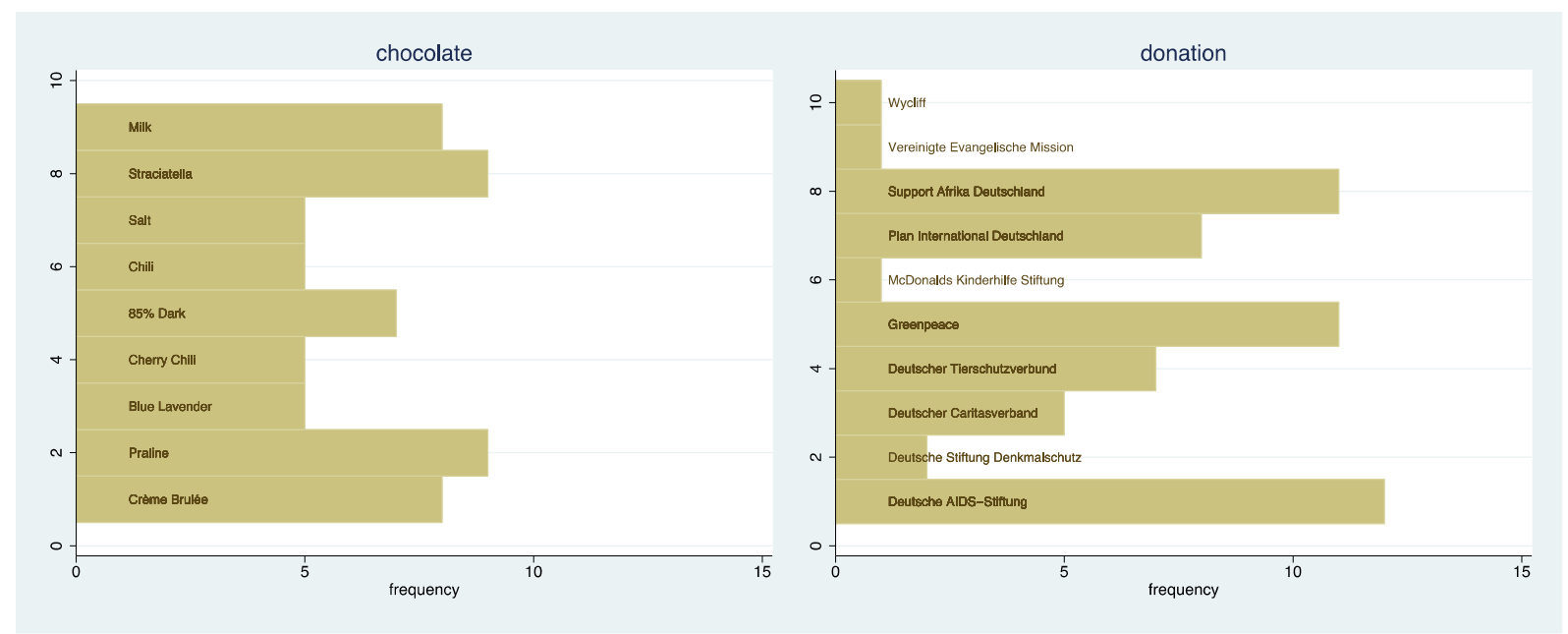

Figure 2

Preferences for Commodities

Our main interest is in efficiency: does the availability of either remedy increase the incidence of mutually beneficial trade? Inspecting Figure 3 we see an obvious difference between our two commodities. A large majority would rather not buy chocolate in the first place, despite the fact that it is subsidized, if there is a salient risk that they will not get their preferred flavor. By contrast, the equivalently salient risk does not deter donations to the same degree. In the Donation treatment, we also see a difference between remedies. There is virtually no difference between expectation and reliance damages. With both remedies, approximately $60 \%$ of all participants do not want to make a donation despite the fact that it is subsidized. This rate goes however down to $46 \%$ if specific performance is available. 
donation
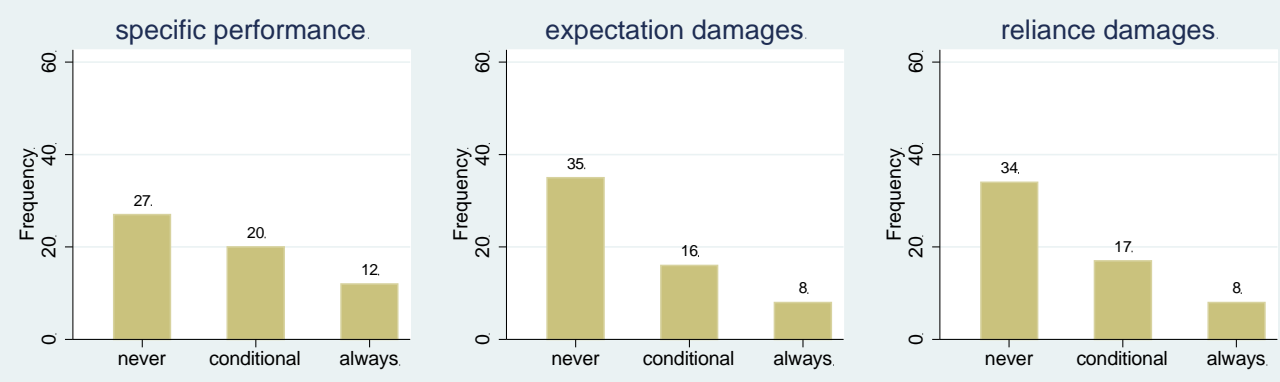

chocolate
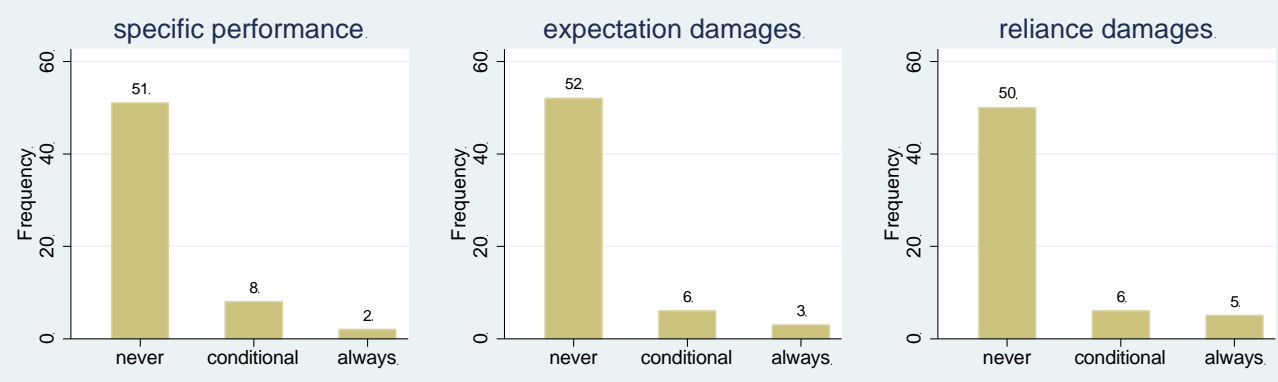

Figure 3

Effect of Remedy on Choices

The visual impression is supported by statistical analysis. We find a significant difference between choices when specific performance is available and choices when only expectation damages are available and the commodity is donations (Wilcoxon, $\mathrm{N}=59, \mathrm{p}=.0027$ ). With donations, we also find a significant difference if we compare choices with specific performance on the one hand and reliance damages on the other hand (Wilcoxon, $\mathrm{N}=59, \mathrm{p}=$ .0047). We do by contrast not find either difference if the commodity is chocolate. We also do not find a difference in choices for donations if the remedy is either expectation or reliance damages, despite the fact that 21/59 participants had a positive willingness to pay for insurance, and would therefore have benefitted from the markup. We thus find qualified support for our hypothesis $\mathbf{H}_{\mathbf{2}}$ that expected the difference to matter for all commodities.

This gives us our main result

Result 1: Participants are more likely to make a donation to their preferred charity if they have a chance to pay for specific performance, rather than for expectation or reliance damages.

We see this as a noteworthy finding. A mere pecuniary markup does not suffice to induce more trade (there is no difference between the expectation and the reliance damage regimes). Participants do not merely care about being made whole for the disutility of not seeing their wishes fulfilled. Their preference for specific performance does not result from the characteristic imperfection in measuring their idiosyncratic preferences (this imperfection is removed 
by the design of the experiment). What they want is not compensation, but the actual fulfillment of the contract. If they are forced to accept compensation in case an exogenous risk materializes, a substantial fraction of them would rather not trade in the first place. From the fact that the same participants are happy to trade if specific performance is available we know that limiting the remedy to either expectation or reliance damages indeed deters trade. Granting specific performance is behaviorally efficient. This result is all the more remarkable as in our experiment specific performance does not come for free. Its cost is also not concealed in the price calculations of the seller. If they want specific performance, participants have to pay for it by a separate transaction.

Figure 4 suggests that choices and willingness to pay are correlated, which is also what we find (specific performance, Pearson $r=.4332$, $\mathrm{p}<.001$; expectation damages, $\mathrm{r}=.3543, \mathrm{p}=$ .0001 ; reliance damages, $\mathrm{r}=.4046, \mathrm{p}<.001$ ). We do not find any significant differences if we treat willingness to pay as a continuous variable, neither non-parametrically nor parametrically. We do however find that, with donations, participants are significantly more likely to pay a positive amount for specific performance rather than expectation damages (Wilcoxon, $\mathrm{N}=59$, $\mathrm{p}=$.0339). With this commodity, we also find a weakly significant difference between the willingness to pay a positive amount for specific performance and for reliance damages (Wilcoxon, $\mathrm{N}=59, \mathrm{p}=.0588$ ). We do not find any differences in the willingness to pay for remedies if the commodity is chocolate. We thus also find qualified support for hypothesis $\mathbf{H}_{\mathbf{1}}$ that expected to find this difference allover.
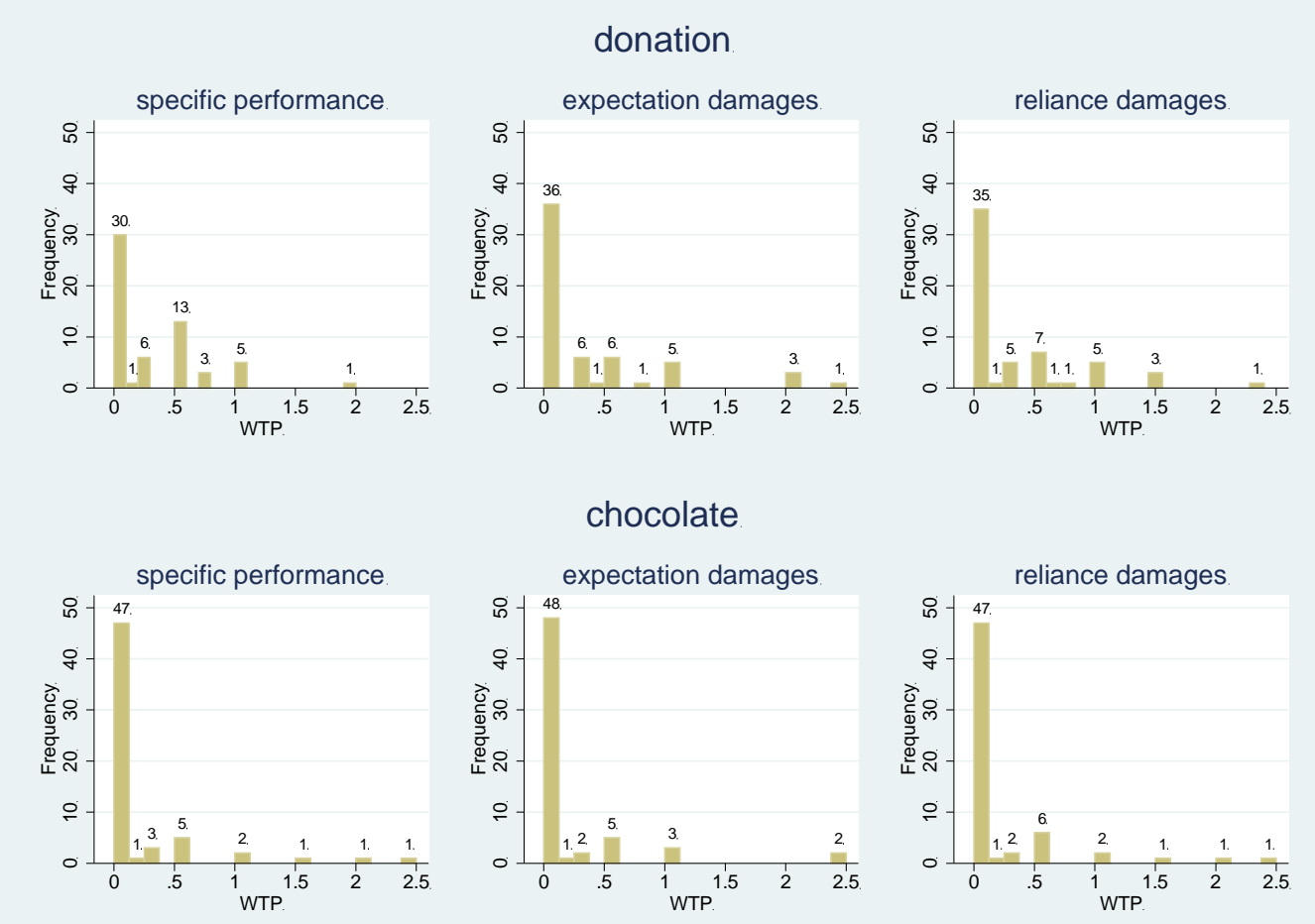

Figure 4

Willingness to Pay for Alternative Remedies 
This gives us

Result 2: Participants are more likely to pay for specific performance, rather than for expectation or reliance damages, if there is a risk that a donation is not received by their preferred charity.

We find that remedies matter for charities but not for chocolate. How can we explain this difference? We turn to the second part of the experiment for the purpose. We had originally designed it as an incentivized measure for the difference between expectation and reliance damages. It turns out that in this part of the experiment we also find the explanation for the between subjects effect. While 51 of 61 participants had no interest in insuring that they would get their preferred chocolate, only 23 of 59 participants refrained from insuring that their donation would go to the desired recipient. This difference is highly significant (Fisher's exact, $\mathrm{p}<.001$ ). The difference is mirrored in willingness to pay. On average, in the Chocolate treatment, participants were only willing to spend 9 Cents on insurance. In the Donation treatment, they were on average willing to spend 29 Cents. This difference too is significant (Mann Whitney, $\mathrm{N}=120, \mathrm{p}=.0071$ ). We conclude from both measures that participants care much more about their preferences over charities than they care about their preferences over flavors of chocolate.

The regressions of Table 1 show that the strength of preferences does not only differ between commodities, but that this difference is critical for the effect. In models 1 we find that the willingness to trade (choice) and the willingness to pay for insurance (WTP $>0$ ) are less pronounced in the Chocolate treatment than in the Donation treatment (main effect of Chocolate). In the Donation treatment (the reference category) the willingness to trade and the willingness to pay for insurance are significantly reduced if only expectation damages or reliance damages are available as a remedy (main effects of expectation damages and reliance damages). Both effects are neutralized in the Chocolate treatment (the main effect and the interaction effect add up to an insignificant net effect close to 0 ).

All main and interaction effects of remedies remain completely unchanged if we control for choices (models 2) and additionally for willingness to pay for insurance in the first part of the experiment (models 3). However with these controls the main effect of the Chocolate treatment is no longer significantly different from zero. If the participant in the first part of the experiment has chosen to make a donation/buy chocolate if the risk is insured, this substantially and significantly increases the likelihood that she makes a donation/buys chocolate in the second part of the experiment, and that she has a positive willingness to pay for insurance in that part of the experiment. The effect on choices is even stronger if, in the first part of the experiment, the participant has decided to donate/buy unconditionally, while this does not make a difference for willingness to pay in the second part of the experiment. Finally willingness to pay for insurance in the first part of the experiment has a significant and substantial positive effect on choices and willingness to pay for insurance in the second part of the experiment. 
If the participant donates/buys unconditionally in the first part of the experiment, she has a very strong preference for helping her charity of choice/receiving her favorite chocolate. This preference is so strong that she is even willing to accept a $25 \%$ risk that her intention fails. If the participant only donates/buys conditionally in the first part of the experiment, either her preference is less strong, or the loss in utility from seeing her preferred charity/flavor replaced by a random selection is too strong to make the deal worthwhile. For our purposes it is not necessary to distinguish between these two motives. It suffices to acknowledge that choices in the second part of the experiment and willingness to pay for insurance in that part of the experiment signal the strength of a participant's preference for one of the charities/the chocolate flavors. It is particularly informative that the commodity main effect ceases to be significant once we control for choices in the second part of the experiment. This indicates that the commodity effect does indeed result from a difference in the strength of preferences. Apparently participants care deeply about donations, while they care much less about buying subsidized chocolate.

\begin{tabular}{|l|l|l|l|l|l|l|}
\hline & \multicolumn{3}{|c|}{ choice } & \multicolumn{3}{c|}{ WTP >0 } \\
\hline & model 1 & model 2 & model 3 & model 1 & model 2 & model 3 \\
\hline expectation damages & $-.203^{\star \star}$ & $-.203^{\star \star \star}$ & $-.203^{\star \star \star}$ & $-.102^{\star \star}$ & $-.102^{\star \star}$ & $-.102^{\star \star}$ \\
& $(.050)$ & $(.050)$ & $(.050)$ & $(.035)$ & $(.035)$ & $(.035)$ \\
\hline reliance damages & $-.186^{\star \star \star}$ & $-.186^{\star \star \star}$ & $-.186^{\star \star \star}$ & $-.085^{\star}$ & $-.085^{\star}$ & $-.085^{\star}$ \\
& $(.050)$ & $(.050)$ & $(.050)$ & $(.035)$ & $(.035)$ & $(.035)$ \\
\hline Chocolate & $-.549^{\star \star \star}$ & -.149 & -.125 & $-.262^{\star \star}$ & -.052 & -.008 \\
& $(.118)$ & $(.099)$ & $(.098)$ & $(.084)$ & $(.084)$ & $(.076)$ \\
\hline Chocolate*expectation & $.203^{\star \star}$ & $.203^{\star \star}$ & $.203^{\star \star}$ & $.085^{+}$ & $.085^{+}$ & $.085^{+}$ \\
damages & $(.071)$ & $(.071)$ & $(.071)$ & $(.048)$ & $(.048)$ & $(.048)$ \\
\hline Chocolate reliance damages & $.252^{\star \star \star}$ & $.252^{\star \star \star}$ & $.252^{\star \star \star}$ & $.085^{+}$ & $.085^{+}$ & $.085^{+}$ \\
& $(.071)$ & $(.071)$ & $(.071)$ & $(.048)$ & $(.048)$ & $(.048)$ \\
\hline part 1 choice conditional & & $.541^{\star \star \star}$ & $.431^{\star \star \star}$ & & $.497^{\star \star \star}$ & $.299^{\star \star}$ \\
& & $(.110)$ & $(.117)$ & & $(.097)$ & $(.094)$ \\
\hline part 1 choice anyway & & $1.204^{\star \star \star}$ & $1.194^{\star \star \star}$ & & $.449^{\star \star \star}$ & $.431^{\star \star \star}$ \\
& & $(.115)$ & $(.113)$ & & $(.101)$ & $(.091)$ \\
\hline WTP part 1 & & & $.247^{\star}$ & & & $.446^{\star \star \star}$ \\
& & & $(.102)$ & & & $(.082)$ \\
\hline cons & $.746^{\star \star \star}$ & $.214^{\star}$ & $.178^{\star}$ & $.492^{\star \star \star}$ & $.203^{\star \star}$ & $.139^{\star}$ \\
& $(.084)$ & $(.085)$ & $(.085)$ & $(.060)$ & $(.073)$ & $(.067)$ \\
\hline $\mathrm{N}$ & 360 & 360 & 360 & 360 & 360 & 360 \\
\hline
\end{tabular}

Table 1

Explaining Treatment Differences With Strength of Preferences

linear random effects, Hausman test insignificant on all models

$\mathrm{N}=360$ since the strategy method gives us 3 choices per participant

dv: choice: 0 never, 1 conditional on being insured, 2 anyway; reference category: never dv: WTP > 0: dummy that is 1 if positive willingness to pay for respective remedy treatment: reference category Donation remedies: reference category: specific performance

part 1 choice conditional: participant has made donation / buying chocolate conditional on being insured part 1 choice anyway: participant has decided to donate / buy chocolate whether or not she is insured WTP part 1: willingness to pay for insurance in part 1 of experiment standard errors in parenthesis $* * * \mathrm{p}<.001, * * \mathrm{p}<.01, * \mathrm{p}<.05,+\mathrm{p}<.1$ 
Based on these findings we conclude

Result 3: The availability of specific performance, rather than expectation damages or reliance damages, only affects the willingness to trade and the willingness to pay for the remedy if preferences for the traded commodity are sufficiently strong.

Choices and willingness to pay for either remedy in the third part of the experiment cannot be explained with measures from post-experimental tests. As the components of a structural model reported in Table 2 demonstrate, some of these measures do, however, explain results from the second part of the experiment. Whether a participant is willing to spend money on a donation (the reference category) is strongly predicted by her social value orientation. Yet for chocolate, the effect is absent (the interaction effect completely neutralizes the main effect of social value orientation). By the same token, if the contract is about donations, willingness to pay for insurance in the second part is significantly predicted by aversion against ethical risk. But through the interaction effect the effect disappears if the object of the contract is chocolate.

Whenever there is a significant effect of a post-experimental measure in the second part of the experiment, there is also an indirect effect in the third part of the experiment. If participants are strongly averse to advantageous equity (have a high social value orientation score) they are more likely to make a donation in the second part of the experiment. Through this channel such participants are also more likely to make a donation in the third part of the experiment. ${ }^{4}$ Likewise participants with a strong aversion to ethical risk have a higher willingness to pay for insurance in the second part of the experiment. Through this channel such participants are also more likely to make a donation in the third part of the experiment if they are more averse to ethical risk. Interestingly aversion to financial risk, measured by the standard test from Holt and Laury (2002), does not explain any dependent variables in this data. It is also remarkable that the estimates for choices in the second part of the experiment, and for willingness to pay in this part of the experiment, are perfectly identical in structural models that, as a third component, either explain choices or willingness to pay for remedies, in the third part of the experiment (Table 2).

4 Technically, indirect effects result from multiplicative effect. In the concrete case, in the structural model, the coefficient of choices in the first part of the experiment on choices in the second part is multiplied with the effect of social value orientation choices in the first part and, using a non-linear Wald test, tested against the nul hypothesis that the multiplicative effect is 0 . 


\begin{tabular}{|c|c|}
\hline choice in part 3 & \\
\hline expectation damages & $\begin{array}{l}-.218^{\star \star \star} \\
(.051)\end{array}$ \\
\hline reliance damages & $\begin{array}{l}.182^{\star \star \star} \\
(.051)\end{array}$ \\
\hline Chocolate & $\begin{array}{l}-.127 \\
(.099) \\
\end{array}$ \\
\hline Chocolate $^{*}$ expectation damages & $\begin{array}{l}.236^{\star *} \\
(.072)\end{array}$ \\
\hline Chocolate ${ }^{\star}$ reliance damages & $\begin{array}{l}.270^{\star \star \star} \\
(.072)\end{array}$ \\
\hline choice in part 2: conditional & $\begin{array}{l}.453^{\star \star \star} \\
(.119)\end{array}$ \\
\hline choice in part 2: anyway & $\begin{array}{l}1.247^{\star \star \star} \\
(.116)\end{array}$ \\
\hline WTP in part 2 & $\begin{array}{l}.239^{\star} \\
(.107) \\
\end{array}$ \\
\hline cons & $\begin{array}{l}.163^{+} \\
(.085)\end{array}$ \\
\hline choice in part 2 & \\
\hline Chocolate & $\begin{array}{l}-.318^{\star *} \\
(.116) \\
\end{array}$ \\
\hline social value orientation & $\begin{array}{l}.019^{\star \star \star} \\
(.005)\end{array}$ \\
\hline Chocolate*social value orientation & $\begin{array}{l}-.021^{* *} \\
(.006)\end{array}$ \\
\hline constant relative risk aversion & $\begin{array}{l}.036 \\
(.070) \\
\end{array}$ \\
\hline cons & $\begin{array}{l}.575^{\star \star \star} \\
(.094)\end{array}$ \\
\hline WTP in part 2 & \\
\hline Chocolate & $\begin{array}{l}.067 \\
(.091)\end{array}$ \\
\hline constant relative risk aversion & $\begin{array}{l}-.029 \\
(.041) \\
\end{array}$ \\
\hline aversion against ethical risk & $\begin{array}{l}.125^{\star \star \star} \\
(.035)\end{array}$ \\
\hline Chocolate*aversion against ethical risk & $\begin{array}{l}-.150^{\star *} \\
(.052)\end{array}$ \\
\hline cons & $\begin{array}{l}.067 \\
(.069)\end{array}$ \\
\hline $\mathrm{N}$ & 336 \\
\hline
\end{tabular}

Table 2

Structural Model

linear structural model

components explaining choices / willingness to pay for insurance in part 1 of the experiment are perfectly identical (and as reproduced here), whether we use choices or willingness to pay in part 2 as the third component model includes random effect for individual participant

$\mathrm{N}<360$ since we drop datapoints from participants who are inconsistent on the test for risk aversion

dv: choice: 0 never, 1 conditional on being insured, 2 anyway; reference category: never

dv: WTP > 0: dummy that is 1 if positive willingness to pay for respective remedy

social value orientation: score from test by Murphy/Ackermann

constant relative risk aversion: score from test by Holt/Laury

aversion against ethical risk: score from test by Blais/Weber standard errors in parenthesis

*** $\mathrm{p}<.001, * * \mathrm{p}<.01, * \mathrm{p}<.05,^{+} \mathrm{p}<.1$ 


\section{Discussion}

Most apparent differences between common and continental law disappear if one looks below the doctrinal surface. While legal orders use very different, historically contingent techniques, much more often than not they decide similar cases in similar ways. This is not a coincidence. If social and economic conditions are similar, it is very likely that legal experts converge to similar solutions. One of the few true differences concerns remedies for breach of contractual obligations. While on the continent the default is specific performance, in common law the default is financial compensation. As reported in the introduction of this paper, justifying the position of common law has been one of the first issues that have made law and economics prominent. Researchers have pointed out that a compensation rule favors ex post efficiency. The two classic illustrations are: seller has promised to produce a commodity, and prices of an input have rocketed; seller has found another buyer who pays a much higher price. In both situations, ex post it is efficient if seller is not forced to fulfill the contract. A second generation of law and economics contributions has criticized the focus on ex post efficiency. From an ex ante perspective, the investment decisions of both parties to the contract come into view.

This paper is meant to contribute to this comparative law dispute from a behavioral perspective. We argue that specific performance is behaviorally efficient. In our experiment we show that the availability of specific performance increases the probability that buyers trade the commodity even if they anticipate that, with some probability, the contract will be impeded from being implemented. If the remedy is specific performance, and not damages, buyers can simply ignore this risk. We show that, if this additional safety is provided, buyers are significantly more likely to trade. They do so despite the fact that, in our experiment, they have to pay for the additional protection with their own money, and by a separate contract. Participants do have a positive willingness to pay for such protection that transcends their willingness to pay for the mere financial interest in contract implementation. This finding is all the more remarkable as our design excludes a difference between specific performance and expectation damages that looms large in the field: we have a credible measure for the monetary equivalent of the difference between receiving a standard product instead and receiving the desired product. Hence participants cannot have disliked expectation damages because they are concerned that compensation might be incomplete.

Interestingly, however, this result only holds if the object of trade is a charitable donation. It does not hold if participants trade chocolate. Using data from the second part of the experiment we are able to show that the efficiency enhancing effect of specific performance is only present if participants have strong preferences for the traded commodity. ${ }^{5}$

Experiments are tools to isolate causal effects. By design, they strip off the situation from contextual factors that might lead to confounds. These simplifications are necessary to make

5 It is beyond the scope of this paper to find the reason why participants have stronger preferences for charities than for chocolate; a likely candidate are social preferences. 
sure that the only possible explanation for a treatment effect is random assignment to treatment, not anything else. The inevitable price is decontextualisation. By design, the situation that one investigates is only analogous to the situation that one wants to understand. We believe, however, that this price is not high in our case. The main simplification is in the relationship. We do not have a contracting party (other than the experimenter). The remedy is not part of the terms and conditions of the contract, but the object of a separate negotiation. The cause of contract failure is not willful action of the contractual partner, but a random draw. We need these simplifications to isolate the difference we are investigating: willingness to engage in mutually beneficial exchange, and willingness to pay, for differently wide reaching protection. Using the strategy method, participants choose for a situation with specific performance, expectation damages and reliance damages. We also make the risk explicit from the outset that the contract might not be fulfilled as desired. These features of the experiment make the difference between specific performance and compensation more salient than it likely is in the field. But on the other hand the design of the experiment completely removes evidentiary problems that loom large in the field. Nonetheless real contractual partners might pay less attention to the limitations of compensation than the participants of our experiment. This would reduce the behavioral inefficiency. We note an additional advantage of our design. Since we frame remedies as insurance, to be bought against a separate price and by a separate contract, the measured preference for specific performance cannot simply be a preference for the type of (main) contract participants are used to get.

A second peculiarity of the experiment are the commodities offered for trade. We only find an efficiency advantage of specific performance if the contract is about charities, not if it is about chocolate. Donations to charities are a rather unusual object of trade. We grant this limitation. We originally had added the Chocolate treatment in the interest of also testing a commodity that is more standard. As we explain in the paper, we do not find an advantage for specific performance for chocolate. While this has not been our intention, in retrospect we believe that comparing the Donations with the Chocolate treatment has allowed us to find an important qualification. Specific performance only increases efficiency if buyers have strong preferences for the quality of a commodity. This will certainly not hold across-the-board. But it is also not an oddity of donations. The results from our experiment do, however, suggest that specific performance is particularly important for commodities with a strong idiosyncratic component.

More generally, our experiment suggests that the legislator and the courts are well advised to take the likely reactions of individuals to legal institutions into account. Even if there would be no difference between two interventions for an individual that maximizes profit, these same two institutions may feel very differently for the true individuals that the law is meant to govern. Such individuals care about more than just profit. One such concern is a strong preference for one commodity over another, which cannot be compensated in money. As our experiment demonstrates, money is not a universal currency. 


\section{References}

Ayres, Ian and Robert Gertner (1999). "Majoritarian vs. Minoritarian Defaults." Stanford Law Review 51: 1591-1613.

Becker, Gordon M., Morris H. DeGroot and Jacob Marschak (1964). "Measuring Utility by a Single-response Sequential Method." Behavioral Science 9(3): 226-232.

Bernheim, B Douglas (2009). "Behavioral Welfare Economics." Journal of the European Economic Association 7(2-3): 267-319.

Bernheim, B Douglas and Antonio Rangel (2009). "Beyond Revealed Preference: Choicetheoretic Foundations for Behavioral Welfare Economics." Quarterly Journal of Economics 124(1): 51-104.

Birmingham, Robert L (1970). "Breach of Contract, Damage Measures, and Economic Efficiency." Rutgers Law Review 24: 273-292.

Blais, Ann-Renee and Elke U. Weber (2006). "A Domain-Specific Risk-Taking (DOSPERT) Scale for Adult Populations." Judgement and Decision Making 1: 33-47.

Bock, Olaf, Ingmar Baetge and Andreas Nicklisch (2014). "hroot: Hamburg Registration and Organization Online Tool." European Economic Review 71: 117-120.

Buijze, Renate, Christoph Engel and Sigrid Hemels (2017). "Insuring Your Donation. An Experiment." Journal of Empirical Legal Studies 14: ***.

Carlyle, Thomas (1849). Occasional Discourse on the Nigger Question.

Depoorter, Ben and Stephan Tontrup (2012). "How Law Frames Moral Intuitions. The Expressive Effect of Specific Performance." Arizona Law Review 54: 673-717.

Fischbacher, Urs (2007). "z-Tree. Zurich Toolbox for Ready-made Economic Experiments." Experimental Economics 10: 171-178.

Friedmann, Daniel (1989). "The Efficient Breach Fallacy." Journal of Legal Studies 18: 1-24.

Goetz, Charles J and Robert E Scott (1977). "Liquidated Damages, Penalties and the Just Compensation Principle. Some Notes on an Enforcement Model and a Theory of Efficient Breach." Columbia Law Review 77(4): 554-594.

Holt, Charles A. and Susan K. Laury (2002). "Risk Aversion and Incentive Effects." American Economic Review 92: 1644-1655.

Kahneman, Daniel, Jack L. Knetsch and Richard Thaler (1990). "Experimental Tests of the Endowment Effect and the Coase Theorem." Journal of Political Economy 98: 13251348. 
Lewinsohn-Zamir, Daphna (2012). "The Questionable Efficiency of the Efficient Breach Doctrine." Journal of Institutional and Theoretical Economics 168: 5-26.

Lewinsohn-Zamir, Daphna (2013). "Can't Buy Me Love. Monetary Versus In-Kind Remedies." University of Illinois Law Review: 151-194.

Macneil, Ian R. (1982). "Efficient Breach of Contract: Circles in the Sky." Virginia Law Review 68: 947-969.

Murphy, Ryan O. and Kurt A. Ackermann (2014). "Social Value Orientation: Theoretical and Measurement Issues in the Study of Social Preferences." Personality and Social Psychology Review 18: 13-41.

Posner, Richard A. (2014). Economic Analysis of Law. New York, Aspen Publishers.

Schweizer, Urs (2006). "Cooperative Investments Induced by Contract Law." Rand Journal of Economics 37(1): 134-145.

Schweizer, Urs (2012). "Breach Remedies, Performance Excuses, and Investment Incentives." Journal of Law, Economics, and Organization 28(4): 717-733.

Selten, Reinhard (1967). Die Strategiemethode zur Erforschung des eingeschränkt rationalen Verhaltens im Rahmen eines Oligopolexperiments. Beiträge zur experimentellen Wirtschaftsforschung. E. Sauermann. Tübingen, Mohr: 136-168.

Sloof, Randolph, Edwin Leuven, Hessel Oosterbeek and Joep Sonnemans (2003). "An Experimental Comparison of Reliance Levels under Alternative Breach Remedies." Rand Journal of Economics 34: 205-222.

Sloof, Randolph, Hessel Oosterbeek, Arno Riedl and Joep Sonnemans (2006). "Breach Remedies, Reliance and Renegotiation." International Review of Law and Economics 26(3): 263-296.

Stremitzer, Alexander (2012). "Standard Breach Remedies, Quality Thresholds, and Cooperative Investments." Journal of Law, Economics, and Organization: 337-359.

Wilkinson-Ryan, Tess (2010). "Do Liquidated Damages Encourage Breach? A Psychological Experiment." Michigan Law Review 108: 633-671.

Wilkinson-Ryan, Tess and David A Hoffman (2010). "Breach is for Suckers." Vanderbilt Law Review 63: 1001-1045.

Wilkinson-Ryan, Tess and Jonathan Baron (2009). "Moral Judgment and Moral Heuristics in Breach of Contract." Journal of Empirical Legal Studies 6(2): 405-423. 
Zeiler, Kathryn and Charles R. Plott (2005). "The Willingness to Pay/Willingness to Accept Gap, the Endowment Effect, Subject Misconceptions and Experimental Procedures for Eliciting Valuations." American Economic Review 95: 530-545. 


\section{Appendix \\ Instructions}

[Chocolate treatment in italics]

Welcome to our experiment. In the following you can, depending on your choices, earn money for yourself and others. Please do therefore read the instructions carefully. The experiment consists of three parts. The current instructions inform you about the first part. Information about parts two and three will be provided as those parts start. At the end of the experiment, either part one of part two will be paid out. Both possibilities have the same probability. Part three will be paid out with certainty.

Please do not talk to each other. If you have questions, please let us know. We will then come and answer them.

\section{Part 1}

In the first part of the experiment you receive $5 €$. You have the possibility to donate $2.50 €$ I spend $2.50 €$ on buying two chocolate bars. If you make a donation, the experimenter adds another 2.50€. If you buy the chocolate in a shop, it would be more expensive. Hence if you make a donation, the charity receives $5 €$ from you, and you keep $2.50 €$. We ask you to pick a charity to which you might possibly make a donation from the list. If you do not want to make a donation, you can indicate this at a later point. However with a probability of $25 \%$, another charity / flavor from the list is chosen. You can insure yourself against this risk. We ask you to state the maximum amount you are willing to pay for making sure that this risk does not materialize. The amount may be between $0 €$ and $2.50 €$. If you do not want to pay anything, please indicate $0 €$. The amount that you have indicated is compared with a randomly chosen number between 0 and $2.50 €$. Now there are two possibilities:

1. If the number you have indicated is the same or larger than the randomly determined number, the charity / flavor that you have selected is chosen with certainty. Your endowment is reduced by the number randomly determined by the computer. If you decide to make a donation, additionally $2.50 €$ is subtracted from your endowment.

2. If the number you have indicated is smaller than the randomly determined number, the charity / flavor that you have selected is chosen with probability $75 \%$. However with a probability of $25 \%$ another charity / flavor from the list is chosen. Each of the other charities / flavors is chosen with equal probability. If you decide to make a donation / buy chocolate, $2.50 €$ is subtracted from your endowment.

All random draws are executed by the computer independently for each participant.

You will have to make the following decision:

Do you want to donate $2.50 €$ / spend $2.50 €$ on buying two chocolate bars?

- only if my charity / flavor is chosen with certainty

- always

- never

We will inform you about results from the first part of the experiment at the end of the entire experiment. 


\section{Part 2}

In the second part you receive another $5 €$, of which you can again donate $2.50 €$ to the charity / spend 2.50€ on buying two bars of the chocolate you have selected. Please note that again the experimenter will add $2.50 €$ to your donation in case you make one. Hence the charity receives $5 €$, and you keep $2.50 €$. [] However for the second donation there is a risk that the entire donation does not reach the intended recipient that no chocolate is acquired. Instead with $25 \%$ probability a person that has been randomly selected from the phonebook of Berlin receives your donation / payment of 2.50€ (as well as the donations / payments of all other participants that are not successfully paid out to their desired charities used for buying the preferred flavor of chocolate). If you do not want to make a donation /buy, you can indicate this at a later point.

You have the possibility to insure yourself against the risk. There are three alternative insurance options, one of which will be randomly selected. More information on these insurance options follows on the next page. It is equally probable for each insurance to be offered. Since you do not know which insurance will be offered, we ask you to indicate, separately for each insurance option, which amount from $0 €$ to $2.50 €$ you are at most willing to pay for insurance. For each insurance option, the number you have indicated will be compared with a randomly chosen number between $0 €$ and $2.50 €$. For each insurance option, there are two possibilities:

1. If the number you have indicated is the same or larger than the randomly determined number, you are insured. Your endowment is reduced by the number randomly determined by the computer. If you decide to make a donation Ibuy chocolate, additionally $2.50 €$ is subtracted from your endowment.

2. If the number you have indicated is smaller than the randomly determined number, you are not insured. Your endowment is not reduced by the number randomly determined by the computer. If you decide to make a donation / buy chocolate, $2.50 €$ is subtracted from your endowment.

All random draws are executed by the computer independently for each participant. However all donations that are not received by the charity / all payments that are not used to buy the chocolate selected by the respective participant are transferred to the same (randomly chosen) person.

For each of the three insurance options, you will have to make the following decision:

Do you want to donate $2.50 €$ / spend $2.50 €$ on buying chocolate?

- only if my charity / flavor is chosen with certainty

- always

- never 


\section{Insurance options}

Insurance \#

Insurance \$

Insurance \&
This insurance guarantees that the charity you have selected receives from you a donation of $5 € /$ receive your selected flavor. If the computer has decided that your original donation / payment goes to the person that has been randomly selected from the Berlin phonebook, the insurance pays $5 €$ to the charity you have selected / buys the chocolate for you. The donation / purchase made by the insurance is not exposed to the risk.

This insurance guarantees a monetary payment in case the donation does not reach the charity / do not receive the chocolate that you have selected. The payment is calculated as follows: you receive

a) the amount you have paid (2.50€) plus

b) the amount you have at maximum been willing in the first part of the experiment to pay to make sure that the donation is paid out to the charity / receive the flavor that you have selected (and not another charity / flavor from the list).

You are again given the opportunity to donate $2.50 €$ / spend $2.50 €$ on buying two bars of chocolate. If you do, the experimenter again adds $2.50 €$. $\square$ This new donation of $5 €$ is, however, received by a randomly chosen charity from the list. The flavor is however randomly chosen from the list. The charity / flavor you have selected cannot receive the second donation / be selected. The second donation / purchase is not exposed to the risk.

This insurance guarantees a monetary payment in case the donation does not reach the charity / do not receive the chocolate that you have selected. The payment is calculated as follows: you receive

the amount you have paid (2.50€).

You are again given the opportunity to donate $2.50 € /$ spend $2.50 €$ on buying two bars of chocolate. If you do, the experimenter again adds $2.50 €$. [ This new donation of $5 €$ is, however, received by a randomly chosen charity from the list. The flavor is however randomly chosen from the list. The charity / flavor you have selected cannot receive the second donation / be selected. The second donation / purchase is not exposed to the risk.

We will inform you about the results from the second part of the experiment at the end of the entire experiment.

[Part 3 is the standard test for risk aversion by Holt \& Laury and SVO by Murphy \& Ackermann.] 


\section{Lists of commodities}

List of chocolate flavors

1. Creation Crème Brûlée

2. Creation Knusper Praliné

3. Edelbitter Mousse Blaubeer-Lavendel

4. Edelbitter Mousse Sauerkirsch Chili

5. Excellence $85 \%$

6. Excellence Chilie

7. Excellence Meersalz

8. Excellence Straciatella

9. Lindor Milch

10. Mocca

\section{List of charities}

1. Deutsche AIDS-Stiftung

2. Deutsche Stiftung Denkmalschutz

3. Deutscher Caritasverband e.V.

4. Deutscher Tierschutzverbund e.V.

5. Greenpeace e.V.

6. McDonald's Kinderhilfe

7. Plan International Deutschland e.V

8. SUPPORT AFRICA DEUTSCHLAND

9. Vereinte Evangelische

10. Wycliff e.V. 